\title{
Non-Saccharomyces Killer Toxins: Possible Biocontrol Agents Against Brettanomyces in Wine?
}

\author{
N.N. Mehlomakulu, M.E. Setati, B. Divol* \\ Institute for Wine Biotechnology, Department of Oenology and Viticulture, Private Bag X1, Stellenbosch University, \\ Stellenbosch, 7600, South Africa
}

Submitted for publication: July 2014

Accepted for publication: August 2014

Key words: Brettanomyces, wine spoilage, killer toxins, non-Saccharomyces yeasts

\begin{abstract}
Red wine spoiled by the yeast Brettanomyces bruxellensis is characterised by off-odours commonly described as horse sweat, phenolic, varnish and band-aid. The growth of this yeast in wine is traditionally controlled by the use of sulphur dioxide $\left(\mathrm{SO}_{2}\right)$. However, the concentration of $\mathrm{SO}_{2}$, the $\mathrm{pH}$ of the wine, the presence of $\mathrm{SO}_{2}$-binding chemical compounds in the wine, as well as the strain of B. bruxellensis, determine the effectiveness of $\mathrm{SO}_{2}$. Other chemical preservatives have been tested, but are not much more efficient than $\mathrm{SO}_{2}$, and methods used to clean barrels are only partially effective. Filtration of wine and the use of electric currents/fields are also reported to alter the physical and sensory properties of wine. In this context, alternative methods are currently sought to achieve full control of this yeast in wine. Killer toxins have recently been proposed to fulfil this purpose. They are antimicrobial compounds secreted by Saccharomyces and non-Saccharomyces yeasts, displaying killer activity against other yeasts and filamentous fungi. They are believed to play a role in yeast population dynamics, and this killer phenotype potentially could be exploited to inhibit the growth of undesired microorganisms within a microbial ecosystem such as that occurring in wine. In this review, non-Saccharomyces killer toxins are described and their potential application in inhibiting $B$. bruxellensis in wine is discussed in comparison to other tried methods and techniques.
\end{abstract}

\section{INTRODUCTION}

Brettanomyces bruxellensis is regarded as a major red wine spoilage yeast. Its occurrence and development in wine are controlled mainly through the use of sulphur dioxide $\left(\mathrm{SO}_{2}\right)$. However, the antimicrobial property of $\mathrm{SO}_{2}$ depends on a number of factors, including the concentration of its molecular fraction, as well as the species and strains of microorganisms that need to be eliminated. Under certain conditions, such as $\mathrm{pH}>4$ and the presence of $\mathrm{SO}_{2}$-binding compounds in wine, the concentration of molecular $\mathrm{SO}_{2}$ drops and the effectiveness of $\mathrm{SO}_{2}$ becomes limited. Furthermore, yeast species and strains have been reported to exhibit a range of tolerance levels vis-à-vis $\mathrm{SO}_{2}$ (Curtin et al., 2012b). Chemical treatments (e.g. benzoic acid and sorbic acid), physical techniques (e.g. filtration, sanitisation) and biologically produced compounds (e.g. the polysaccharide chitosan) have been tested for controlling B. bruxellensis growth and were proven to have limited efficiency (Suárez et al., 2007). In addition, hypersensitivity to $\mathrm{SO}_{2}$ in some wine consumers has spurred the demand for the use of nonchemical preservatives (Comitini et al., 2004a; Lustrato et al., 2006). Alternative methods therefore currently are being sought to control the growth of B. bruxellensis. Biological antimicrobial compounds, such as killer toxins secreted by certain non-Saccharomyces yeasts, including Kluyveromyces wickerhamii, Pichia anomala, Pichia membranifaciens and the filamentous fungi Ustilago maydis, have recently been described as such possible alternatives (Comitini et al., 2004b; Santos et al., 2009; 2011).

Killer toxins are proteinaceous antimicrobial compounds produced by yeasts and are active against members of the same species or closely related species (Lowes et al., 2000). Killer toxin-secreting species are found in Saccharomyces yeasts, as well as in non-Saccharomyces genera such as Debaryomyces, Kluyveromyces, Candida, Hansenula, Pichia, Cryptococcus, Torulopsis, Hanseniaspora and Zygosaccharomyces (Van Vuuren \& Jacobs, 1992; Schmitt \& Breinig, 2006). Non-Saccharomyces killer toxins exhibit a broader spectra of activity, inhibiting species within the nonSaccharomyces and the Saccharomyces genera, compared to those of Saccharomyces (Ciani \& Comitini, 2011). This phenotype (i.e. the secretion of killer toxin) thus could play a pivotal role in governing yeast-yeast interactions and be exploited to control the growth of undesired microorganisms in wine. In this context, the use of these killer toxins can be viewed as the equivalent of bacteriocins, which are applied successfully in fermented and unfermented foods (Cleveland

*Corresponding author: E-mail address: divol@sun.ac.za

Acknowledgements: The financial assistance of the National Research Foundation (NRF), South Africa (Grant specific unique reference numbers (UID) 70999 and 91977) towards this research is hereby acknowledged. Opinions expressed and conclusions arrived at, are those of the authors and are not necessarily to be attributed to the NRF. 
et al., 2001). Killer toxins indeed have been shown to have potential applications in food, agriculture and medical industries (Palpacelli et al., 1991; Lowes et al., 2000; Cailliez et al., 1994; Walker et al., 1995; Goretti et al., 2009; Liu \& Tsao, 2009). The purpose of this review is to draw up a record of the current knowledge on non-Saccharomyces killer toxins and their possible application in winemaking conditions, versus methods and techniques currently used or applied as preservatives in wine.

\section{DEKKERA/BRETTANOMYCES SPOILAGE IN WINE}

In red wine, the yeast Dekkera bruxellensis or its anamorph, B. bruxellensis, produces a range of off-flavour compounds, amongst which ethylphenols are the most potent. Consequently, the production of the latter has been identified as the main spoilage reaction of this yeast in wine (Dias et al., 2003a). B. bruxellensis is spread within the winery environment through the importation of contaminated wine, poor sanitation of hoses, tanks and wooden barrels, or through the passive adherence to the body of the fruit fly (Fugelsang \& Edwards, 2007). The yeast is characterised as a slow grower and is detected in low numbers in the early stages of winemaking (Fugelsang \& Edwards, 2007). It is also tolerant to high ethanol and low sugar concentrations (Wedral et al., 2010). Furthermore, some strains are either tolerant or sensitive to free $\mathrm{SO}_{2}$ above $30 \mathrm{mg} / \mathrm{L}$ (Oelofse et al., 2008). It has also been reported that $B$. bruxellensis can enter into a viable but non-culturable (VBNC) state, which is characterised by reduced metabolic activity, inability to reproduce on solid media and reduced cell size (Millet \& Lonvaud-Funel, 2000). The VBNC state can be maintained throughout alcoholic fermentation when the levels of molecular $\mathrm{SO}_{2}$ are higher and oxygen is limited. The interval between the end of alcoholic fermentation and the beginning of malolactic fermentation (MLF) represents a critical period during which $B$. bruxellensis can exit $\mathrm{VBNC}$ and grow to detectable levels (Fugelsang \& Edwards, 2007) due to the low molecular $\mathrm{SO}_{2}$ concentration at this stage. Furthermore, the availability of residual sugars, assimilable nitrogencontaining compounds (although limited), as well as microaerobic conditions found during ageing in wooden barrels after MLF, also support the proliferation of B. bruxellensis (Chatonnet et al., 1995; Ciani et al., 2003; Comitini et al., 2004b; Oelofse, 2008).

This population of $B$. bruxellensis may be significant enough to produce detectable levels of volatile phenols, e.g. 4-ethylphenol and 4-ethylguaiacol (Chatonnet et al., 1995; Dias et al., 2003b). Red wines are particularly prone to the development of B. bruxellensis and the subsequent production of ethylphenols compared to white wines (Romano et al., 2008), due to Vitis vinifera red varietals that contain precursor phenolics, e.g. non-flavonoid and flavonoid (Monagas et al., 2006; Wedral et al., 2010). Volatile phenols are indeed produced in wine through the catabolism of three different hydroxycinnamic acids: $p$-coumaric, ferulic and caffeic acids. These precursors originate from grapes and therefore are naturally present in grape juice and wine. B. bruxellensis enzymatically converts hydroxycinnamic acids to volatile phenols in a two-step reaction. The precursors are converted by a cinnamate decarboxylase into hydroxystyrenes (4-vinylphenol, 4-vinylguaiacol and 4-vinylcatechol) and further reduced to ethyl derivatives (4-ethylphenol, 4-ethylguaiacol and 4-ethylcatechol respectively) by a vinylphenol reductase. The presence of ethylphenols is characterised by the development of unpleasant odours and tastes that deeply affect wine aroma (Oelofse et al., 2008).

Until about two decades ago, lactic acid bacteria (LAB) were thought to contribute to the production of ethylphenols in wine (Chatonnet et al., 1992). However, Chatonnet et al. (1995) found that, under winemaking conditions, these bacteria only produce ethylphenols at a concentration $<10 \mu \mathrm{g} / \mathrm{L}$. The yeast Pichia guilliermondii may produce $8 \mathrm{mg} / \mathrm{L}$ and $12 \mathrm{mg} / \mathrm{L}$ 4-ethylphenols in red and white grape juice respectively (Barata et al., 2006) compared to other Pichia spp., Torulaspora spp. and Zygosaccharomyces spp., which cannot produce ethylphenols due to the inactivity of their vinylphenol reductase enzyme (Chatonnet et al., 1995). Nevertheless, the production of vinylphenols and ethylphenols in wine is mainly attributed to B. bruxellensis, as both its phenolic acid decarboxylase and vinyl phenol reductase enzymes are active (Dias et al., 2003a; 2003b; Harris et al., 2009; Granato et al., 2014). Over the years, several research teams have attempted to isolate these two enzymes and to characterise their properties (Godoy et al., 2008; Tchobanov et al., 2008; Benito et al., 2009; Godoy et al., 2009; Harris et al., 2009). Although these authors were able to study the kinetic properties of these enzymes, the influence of wine-related inhibitory compounds thereof, as well as their optimal $\mathrm{pH}$ and temperature activity, their isolation remained partial and no genetic sequence could be retrieved. Indeed, it was only very recently that the corresponding genes were identified in the genome of B. bruxellensis (Curtin et al., 2012a; Piškur et al., 2012; Granato et al., 2014). Interestingly, the phenolic acid decarboxylase-encoding gene was shown to be more closely related to its bacterial equivalents (Curtin et al., 2012a), and the vinyl phenol reductase-encoding gene to be a $\mathrm{Cu} / \mathrm{Zn}$ dioxide dismutase displaying strong vinyl phenol reductase activity (Granato et al., 2014). This probably explains the earlier difficulties to isolate these genes in B. bruxellensis. These latest discoveries constitute a major step in understanding the spoilage mechanism of $B$. bruxellensis in wine and will certainly open new research avenues.

The production and sensorial perception of volatile phenols is dependent on the strain and population of B. bruxellensis, the presence of volatile compound precursors and also the variety of grapes used (Suárez et al., 2007; Wedral et al., 2010; Kheir et al., 2013). Suárez et al. (2007) reported the sensory threshold of 4-ethylphenol to be $230 \mu \mathrm{g} / \mathrm{L}$, while Loureiro and Malfeito-Ferreira (2003) reported a preference threshold of $620 \mu \mathrm{g} / \mathrm{L}$. However, these threshold levels can also vary due to the perception of the individual, which is influenced by the wine style, cultivar and the consumer's perceptive abilities (Oelofse, 2008). Furthermore, Romano et al. (2008) reported on the complexity of correlating ethylphenol concentration and the "Brett character" in wines due to the masking effect of other metabolites. The production of these volatile phenols in red wine thus can be prevented by controlling or eliminating B. bruxellensis populations in grape must or wine. Subsequently, several 
strategies have been employed to control wine spoilage by B. bruxellensis.

\section{CONTROL OF B. BRUXELLENSIS SPOILAGE IN WINE \\ Chemical preservatives}

$\mathrm{SO}_{2}$ is the most commonly used chemical preservative in winemaking due to its antioxidant and antimicrobial properties. However, its use and effectiveness in controlling B. bruxellensis are often contradictory in the literature. The contradiction probably arises from the lack of studies under comparable conditions and variability in strain behaviour, as noted by Barata et al. (2008). Low pH values ( 3.5), $\mathrm{SO}_{2}$ levels around $0.8 \mathrm{ppm}$ of molecular $\mathrm{SO}_{2}$ and low ageing temperatures $\left(10\right.$ to $\left.15^{\circ} \mathrm{C}\right)$ are ordinary practices that can be used to limit $B$. bruxellensis activity in wines (Couto et al., 2005). Although $\mathrm{SO}_{2}$ has had a long history of use as a preservative in alcoholic beverages, especially in wines, it can have adverse effects on the respiratory system of consumers (Freedman, 1977). For this reason, alternatives have been sought with more or less success.

Benzoic acid effectively inhibits $B$. bruxellensis growth in soft drinks at concentrations of between 100 and $200 \mathrm{mg} / \mathrm{L}$, and it also inhibits the action of the enzymes hydroxycinnamate decarboxylase and vinylphenol reductase at concentrations between 150 to $200 \mathrm{mg} / \mathrm{L}$ at $\mathrm{pH} 3.6$ (Van Esch, 1992). However, the addition of benzoic acid to wine is not permitted as it affects wine flavour (Benito et al., 2009). Sorbic acid is unable to inhibit B. bruxellensis growth at the concentrations legally permitted (200 to 250 $\mathrm{mg} / \mathrm{L}$ ) (Benito et al., 2009). It has indeed been shown that this yeast is tolerant of $950 \mathrm{mg} / \mathrm{L}$ of sorbic acid at $\mathrm{pH} 3.5$ (Loureiro \& Malfeito-Ferreira, 2006). The use of weak acids such as benzoic and sorbic acid relies mainly on their effectiveness in their undissociated form, therefore, for complete growth control, they need to be added in high concentrations (Du Toit \& Pretorius, 2000). Renouf et al. (2008) found that dimethyl dicarbonate (DMDC) inhibits the growth of B. bruxellensis at $150 \mathrm{mg} / \mathrm{L}$ and can limit the growth of $B$. anomalus at $400 \mathrm{mg} / \mathrm{L}$, which is double the legal limit (Du Toit \& Pretorius, 2000; OIV (International Organisation of Vine and Wine), 2001; Benito et al., 2009). The minimum inhibitory concentration (MIC) of DMDC to kill D. bruxellensis was in fact found to be $100 \mathrm{mg} / \mathrm{L}$, but this is dependent on the initial cell concentration (Costa et al., 2008). Furthermore, the use of DMDC can affect alcoholic fermentation negatively if added to grape juice, as $200 \mathrm{mg} / \mathrm{L}$ of DMDC added to inoculated grape must showed a four-day fermentation delay (Delfini et al., 2002). For further reviews on these methods, see Suárez et al. (2007) and Oelofse (2008). A triplet combination of lauric arginate, cinnamic acid and sodium benzoate was found to inhibit the growth of B. bruxellensis (Dai et al., 2010), although this method would not be suitable in practice. Overall, chemical preservatives have been used successfully for many years to combat microbial contaminants in different beverages. However, their use in wine clearly remains limited due to their negative influence on fermentation kinetics and on the organoleptic properties of wine.

\section{Physical and physicochemical methods}

The separation of microbial cells from wine, cleaning of winery equipment and sanitisation of barrels, and most recently the application of electric currents to wine, are some of the physical methods that have been tested to inhibit the growth of B. bruxellensis. Filtration technology requires the use of membranes with specific porosity; however, this has certain limitations (Zuehlke et al., 2013). For instance, the cell size of $B$. bruxellensis may shrink after exposure to $\mathrm{SO}_{2}$; in this case, filtration with a $0.45-\mu \mathrm{m}$ membrane filter has been shown to be inefficient in removing B. bruxellensis (Millet \& Lonvaud-Funel, 2000). Umiker et al. (2013) suggest the use of membrane filters with porosities of $<0.8 \mu \mathrm{m}$ for the removal of $B$. bruxellensis in wines, but this is contradictory to the previous finding. Moreover, filtration may reduce colour intensity, and the concentration of aroma compounds, esters and phenolic compounds (Peri et al., 1988; ArriagadaCarrazana et al., 2005; Moreno \& Azpilicueta, 2006). Barrel sanitation by steam treatment and burning of sulphur are not enough to eliminate $B$. bruxellensis (Loureiro \& MalfeitoFerreira, 2003), and the organism cannot be removed by cleaning or shaving of barrels (Wedral, 2010). Other methods, such as thermal inactivation, ultrasound or highpower ultrasonics, have been shown to be effective against Brettanomyces or Dekkera species. Couto et al. (2005) found that D. bruxellensis was inactivated at $35^{\circ} \mathrm{C}$, while Yap et al. (2008) and Schmid et al. (2011) reported that the use of highpressure ultrasound or high-power ultrasonics eliminated the population of $D$. bruxellensis in wine barrels.

Pulsed electric fields and UV-C (ultra violet) radiation have also been investigated. The use of pulsed electric fields (PEF) reduced the population of D. bruxellensis and D. anomala in must and wine (Puértolas et al., 2009), and the same was observed against $D$. bruxellensis in wine using a low electric current (LEC) (Lustrato et al., 2010). However, the effect of PEF on the sensorial properties of wine and the evaluation of the ability of this technology in wineries still needs to be researched further (Marsellés-Fontanet et al., 2009). The use of UV-C radiation in must and wine resulted in the reduction of $B$. bruxellensis, L. plantarum and $S$. cerevisiae. However, the reduction and complete inactivation of the microbial population in must and wine was observed when UV-C dosages of $3672 \mathrm{~J} / \mathrm{L}$ were applied, which was dependent on the initial microbial load, turbidity and colour of the liquid sample (Fredericks et al., 2011).

The application of physicochemical methods such as the use of biocide ozone $\left(\mathrm{O}_{3}\right)$ to inactive the population of B. bruxellensis was recently investigated by Guzzon et al. (2013). The activity of $\mathrm{O}_{3}$ was found to be dependent on the initial cell population. Furthermore, a 10 min treatment with ozonated water was more effective in winery CIP (cleaning in place) systems than peracetic acid or caustic soda cleaning agents. However, when $\mathrm{O}_{3}$ is used, attention must be paid to recommended dosages and limited human exposure (Guillen et al., 2010). Although these methods have been shown to be efficient in inhibiting or even eliminating Brettanomyces and Dekkera species, their activity is mainly dependent on the initial load of the cell concentration to be eliminated. 


\section{Biological methods}

Biological methods have been shown to be alternatives compared to the use of chemical preservatives or physical treatments. It was found recently that the use of a commercial enzyme solution containing an endo- $\beta(1-3)$-glucanase, exo$\beta(1-3)$-glucanase, exo- $\beta(1-6)$-glucanase and an unspecific $\beta$-glucosidase inhibited the growth of $D$. bruxellensis and $Z$. bailii by more than $90 \%$. The solution resulted in a half maximal inhibitory concentration $\left(\mathrm{IC}_{50}\right)$ and $\mathrm{MIC}$ at $115 \mu \mathrm{g} / \mathrm{mL}$ and $200 \mu \mathrm{g} / \mathrm{mL}$ respectively on both yeasts (Enrique et al., 2010). Chitosan, the deacetylated derivative of chitin, was found to have a fungistatic effect against B. bruxellensis and, at concentrations $>3 \mathrm{~g} / \mathrm{L}$, the yeast ceased to survive (Gómez-Rivas et al., 2004). Recently, Oro et al. (2014) showed that Metschnikowia pulcherrima secretes pulcherriminic acid, which is inhibitory to the growth of B. bruxellensis. Finally, in recent studies, the use of biological antimicrobial compounds, such as the killer toxins Kwkt, Pikt and PMKT2 from the yeast species $K$. wickerhamii, $P$. anomala and $P$. membranifaciens respectively, was shown to be successful in inhibiting Dekkera/Brettanomyces in wine, and these will be discussed in the next section.

\section{KILLER TOXINS}

\section{General considerations}

Killer toxins are defined as antimicrobial proteinaceous compounds that inhibit susceptible yeast species or strains, although they remain immune to their own toxins (Bussey, 1972; Magliani et al., 1997; Schmitt \& Breinig, 2002; Lowes et al., 2009). Yap et al. (2000) termed the secretion of killer toxins "interference competition", a form of amensalism. Although interference competition favours the growth of the killer toxin-producing yeast over that of other microorganisms present in the same habitat, its potential role in eliminating undesired microorganisms cannot be disputed. Thus, this killer phenotype can be used to combat spoilage yeasts and can be used as a partial substitute to chemical agents such as $\mathrm{SO}_{2}$ for the preservation of wine (Ciani \& Comitini, 2011).

Non-Saccharomyces yeast genera such as Debaryomyces, Kluyveromyces, Candida, Hansenula, Pichia, Cryptococcus, Torulopsis, Hanseniaspora, Zygosaccharomyces and yeast species of the Saccharomyces genus are reported to secret killer toxins (Van Vuuren \& Jacobs, 1992; Schmitt \& Breinig, 2006). Four phenotypes have been identified: killer, sensitive, neutral and killer-sensitive phenotypes. A specific killer strain produces a toxin and is immune to it; a sensitive strain does not produce the toxin and is sensitive to the toxin produced by a killer strain; a neutral strain neither produces nor is sensitive to the killer toxin produced by a killer strain (Gutiérrez et al., 2001), and a killer-sensitive strain produces a toxin and is immune to it but is sensitive to toxins produced by other strains (Tredoux et al., 1986).

\section{Killer toxins of $S$. cerevisiae}

S. cerevisiae's killer toxins were first discovered in 1963 (Woods \& Bevan, 1968). Four killer toxins have been identified so far: K1, K2, K28 and Klus. S. cerevisiae's killer toxins are encoded by different cytoplasmically inherited satellite double stranded RNAs (dsRNAs) (M1, M2, M28 and Mlus) encapsulated in virus-like particles (VLPs) and are dependent on helper yeast viruses (L-A) for their replication and encapsidation (Magliani et al., 1997; Schmitt \& Breinig, 2006; Rodríguez-Cousin, 2011). The killer activity of $S$. cerevisiae is mainly dependent on the killer:sensitive ratio. These killer toxins have a narrow spectrum of activity, inhibiting only strains or species within the same genus (Mannazzu et al., 2002), except for the Klus killer toxin, which is active against yeasts such as Hanseniaspora spp., Kluyveromyces lactis, Candida albicans, Candida dubliniensis, Candida kefir and Candida tropicalis, and the $\mathrm{K} 1$, K2 and K28 killer strains of $S$. cerevisiae (RodríguezCousin et al., 2011). Considering that these toxins are not active against $B$. bruxellensis they will not be discussed further in this review. For further reading on S. cerevisiae's killer toxins, the reader is advised to consult the following reviews: Magliani (1997), Schmitt and Breinig (2002; 2006) and Rodríguez-Cousin et al. (2011).

\section{Killer toxins secreted by non-Saccharomyces yeasts}

Non-Saccharomyces yeasts exhibiting killer activity were first reported by Philliskirk and Young (1975) in six yeast genera: Debaryomyces, Hansenula, Kluyveromyces, Pichia, Candida and Torulopsis. Young and Yagiu (1978) then identified the killer toxins K4 in Torulopsis glabrata NCYC 388, K5 in Debaryomyces vanriji NCYC 577, Hansenula anomala NCYC 434 and Hansenula subpelliculosa NCYC 16, K6 in Kluyveromyces fragilis NCYC 587, K7 in Candida valida NCYC 327 and P. membranifaciens NCYC 333, K8 in Hansenula anomala NCYC 435, K9 in Hansenula mrakii NCYC 500, and K10 in Kluyveromyces drosophilarum NCYC 575, based on cross-reactivity assays with each of the killer strains. One year later, Wickner (1979) reported that Torulopsis glabrata ATCC15126 also secretes a killer toxin, named K11. Non-Saccharomyces killer toxins originate either from linear dsDNA plasmids or chromosomes (Marquina et al., 2002; Liu et al., 2013), with the notable exception of the killer toxins of $H$. uvarum and $Z$. bailii, which originate from virus-like particles (Schmitt \& Neuhausen, 1994), similar to those of $S$. cerevisiae.

Killer toxins have found application in the food and fermentation industry, the bio-typing of medically important pathogenic yeast and yeast-like fungi, the development of novel antimycotics for the treatment of human and animal infections by fungi, and in recombinant DNA technology (Schmitt \& Breinig, 2002; Liu et al., 2013). Table 1 summarises the genetic, enzymatic and biochemical characteristics of non-Saccharomyces killer toxins with potential application in the food and beverage industry. It also highlights the proposed application of these killer toxins.

\section{Antimycotic activity and application of non- Saccharomyces killer toxins in wine making}

Non-Saccharomyces' killer toxin-producing yeasts have been isolated from various environments, such as marine and clinical environments, as well as fermented and unfermented foods and beverages (Ciani \& Comitini, 2011). These killer toxins exhibit broader anti-yeast spectra compared to those of Saccharomyces (Palpacelli et al., 1991; Ciani \& Comitini, 2011). For instance, the species Tetrapisispora phaffii and 


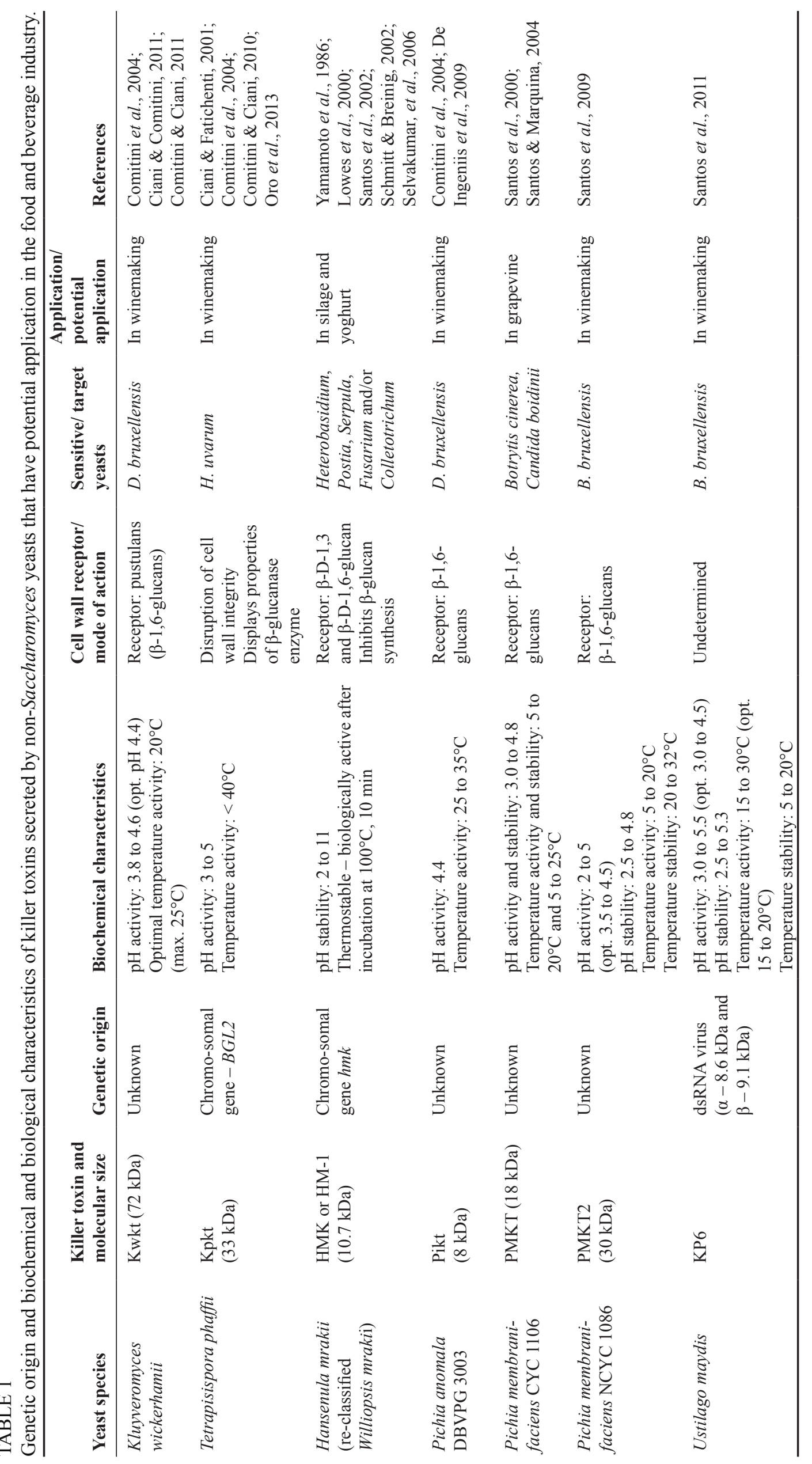


Kluyveromyces wickerhamii display killer activity against the apiculate yeast Hanseniaspora uvarum and species of the Brettanomyces/Dekkera genus respectively (Ciani \& Fatichenti, 2001; Comitini et al., 2004a). Since the first record of a killer toxin inhibiting an apiculate yeast (Ciani \& Fatichenti, 2001), several studies focusing on yeast killer toxins have been conducted with the aim of eliminating undesired yeasts within the wine environment. The killer toxins KwKt, PiKt, PMKT2 and KP6 secreted by the yeasts $K$. wickerhamii, $P$. anomala, $P$. membranifaciens and the filamentous fungi Ustilago maydis have been shown to inhibit the growth of $B$. bruxellensis and D. bruxellensis under winemaking conditions (Comitini et al., 2004b; Santos et al., 2009; 2011).

The killer activity of these toxins was found to be either fungistatic or fungicidal, depending on the killer toxin concentration applied (Ciani \& Fatichenti, 2001). The fungicidal character of the Kwkt killer toxin was observed when 28.6 and $57.2 \mathrm{AU} / \mathrm{mL}$ of the toxin were applied to D. bruxellensis cells (Comitini et al., 2004b). Kwkt controlled the growth of D. bruxellensis during must fermentation, where, after four and seven days, the yeast ceased to survive at purified killer toxin concentrations of $80 \mathrm{mg} / \mathrm{mL}$ and $40 \mathrm{mg} / \mathrm{mL}$, respectively (Comitini \& Ciani, 2011). The same yeast species saw its population diminished only when $28.6 \mathrm{AU} / \mathrm{mL}$ of the killer toxin Pikt was used compared to the use of $57.2 \mathrm{AU} / \mathrm{mL}$, at which a fungicidal effect was observed (Comitini et al., 2004b). In grape must, the killer toxin PMKT2 at $2000 \mathrm{AU} / \mathrm{mL}$ resulted in death rates of $0.13 \mathrm{~h}^{-1}, 0.09 \mathrm{~h}^{-1}$ and $0.11 \mathrm{~h}^{-1}$ in three $B$. bruxellensis strains, as described by Santos et al. (2009). B. bruxellensis isolates had mortality rates ranging between $0.10 \mathrm{~h}^{-1}$ and $0.18 \mathrm{~h}^{-1}$ in mixed cultures with the filamentous fungi U. maydis at $10^{2}$ cells $/ \mathrm{mL}$ (Santos et al., 2011).

The growth of the apiculate yeast H. uvarum was inhibited by immobilised cells of the yeast $T$. phaffii (Comitini \& Ciani, 2010), as well as by the Kpkt killer toxin secreted by T. phaffii (Ciani \& Fatichenti, 2001). Similar to the killer toxins Kwkt and Pikt, Kpkt showed a fungistatic effect at low concentrations of 5.14 and $7.15 \mathrm{AU} / \mathrm{mL}$ compared to 14.3 AU/mL, at which a fungicidal effect was observed in grape juice (Ciani \& Fatichenti, 2001). Under winemaking conditions, the killer toxin Kwkt is efficient and comparable to the use of $\mathrm{SO}_{2}$ in inhibiting $B$. bruxellensis (Comitini \& Ciani, 2011). Furthermore, the killer toxins Kwkt and Pikt maintain their killer activity for 10 days in wine (Comitini et al., 2004b). The killer toxins active against $B$. bruxellensis are active and stable at acidic $\mathrm{pH}$ ranges (below 5), and at temperatures between 20 and $25^{\circ} \mathrm{C}$ (Table 1), which are compatible with winemaking conditions. Furthermore, in trial fermentations in which these killer toxins were applied, the population of $S$. cerevisiae was not inhibited (Santos et al., 2009; Comitini \& Ciani, 2011; Santos et al., 2011). In addition, the metabolic by-products ethyl acetate and 4-ethylphenol, were not detected and volatile acidity was reduced (Comitini \& Ciani, 2011; Santos et al., 2011), further confirming the antimicrobial efficiency of these killer toxins.

\section{MODE OF ACTION OF THE KILLER TOXINS}

Killer toxins are reported to be proteins or glycoproteins that kill sensitive cells via a two-step mode of action similar to that determined for the killer toxins of $S$. cerevisiae. For the toxin to fully initiate its killing action, it interacts with receptors of the sensitive cell wall and receptors on the plasma membrane. There are two kinds of receptors: primary and secondary. The former are located on the cell wall and the latter on the plasma membrane (Guo et al., 2012). The identified primary receptors include $\beta$-D-1,3-glucan, $\beta$-D1,6-glucan, mannoproteins and chitin, while Krelp of the $\mathrm{K} 1$ toxin is the only secondary receptor that has been identified so far (Schmitt \& Breinig, 2002). Mechanisms of the actual killing action differ, and may be through cell membrane permeabilisation, perturbation of the cell cycle and inhibition of DNA synthesis, inhibition of $\beta$-1,3-glucan synthase activity and/or hydrolysis of the major cell wall components, $\beta$-1,3-glucans and 1,6-glucans, of the sensitive strain (Schmitt \& Breinig, 2006; Manzanares et al., 2011). These mechanisms are summarised below.

Ionophoric killer toxins firstly bind to the cell wall receptors of the target yeast with low-affinity and highvelocity adsorption. This is followed by a high-affinity, low-velocity, energy-dependent interaction of the toxin with the plasma membrane receptor that leads to the lethal effect (Magliani et al., 1997). After reaching the plasma membrane, the toxin disrupts cytoplasmic membrane function by forming cation-selective ion channels. This results in the increased permeability of $\mathrm{H}^{+}$(Novotná et al., 2004), and leakage of intracellular ATP, $\mathrm{K}^{+}$(Skipper \& Bussey, 1977) and AMP (Bussey \& Skipper, 1975).

The action of the killer toxins appears not to be immediate. When tested against $S$. cerevisiae sensitive cells, the use of the killer toxin Pikt resulted in 3.5\% viable cells after $24 \mathrm{~h}$ of incubation, compared to $75 \%$ viable cells after $4 \mathrm{~h}$ of incubation. This indicates that the mode of action of this toxin is not immediate and that it is not mediated by cell membrane disruption (De Ingeniis et al., 2009). This toxin has also been reported to display activity against $B$. bruxellensis, but its specific mode of action against this yeast has not been described. However, it is likely to be similar to that against $S$. cerevisiae. The delay in the decline of the sensitive yeast population observed for Pikt is not unique, as it has also been observed following exposure of the $S$. cerevisiae cells to both the pool efflux-stimulating toxins (PEST) and killer toxin of T. glabrata, where after 30 minutes, 60 to $70 \%$ of sensitive cells exhibit uptake of the lethal dose of PEST without any visible metabolic change (Bussey \& Skipper, 1975). However, after a lag time of 50 to 90 minutes, sensitive cells treated with a P. kluyveri toxin exhibited physiological changes observed when ionophoric toxins act on sensitive cells. The cells had shrunk, intracellular $\mathrm{pH}$ had decreased and the active uptake of amino acids was inhibited (Middelbeek et al., 1980) (Fig. 1). High doses of the PMKT2 toxin resulted in a decrease in intracellular $\mathrm{pH}$, leakage of $\mathrm{K}^{+}$and influx of $\mathrm{Na}^{+}$(Fig. 1) which was in parallel to the loss of cellular permeability after $5 \mathrm{~h}$ of toxin exposure, when viability was decreased by $85 \%$. Santos et al. (2013) concluded that PMKT2 cytotoxic action is not 
through channel formation but through the toxin attacking cells after initiating the $\mathrm{S}$ phase (Santos et al., 2013). This mode of action was investigated in $S$. cerevisiae, but is likely to be similar in B. bruxellensis as this toxin displays activity against both yeast species; however, this would need confirmation. This observation is similar to the mode of action of the killer toxin of $K$. lactis, which causes permanent arrest of the sensitive cells at the unbudded G1 phase (Fig. 1) (Magliani et al., 1997), and of the K28 killer toxin, which arrests cells in the early $\mathrm{S}$ phase and blocks DNA synthesis in the cell cycle, leading to the non-separation of mother and daughter cells (Magliani et al., 1997; Couto et al., 2005).

The killer toxin Kpkt is reported to disrupt cell wall integrity of the target cells (Comitini et al., 2009), while Kwkt, a killer toxin active against $B$. bruxellensis, is only reported to bind to $\beta-1,6$-glucan on the cell wall of the sensitive yeast (Table 1) (Ciani \& Comitini, 2011). However, their modes of action are yet to be identified. The KP6 killer toxin secreted by $U$. maydis's mode of action is also thought to be involved with the cell wall of the sensitive cell. Upon exposure to the toxin, the sensitive cells seemed to collapse and change in morphology. Furthermore, spheroplasts of the sensitive cells were not affected by the killer toxin (Steinlauf et al., 1988). The killer toxin HMK, secreted by Hansenula mrakii, inhibits $\beta$-glucan synthesis (Fig. 1) (Yamamoto et al., 1986). More recently, it has been reported that $W$. anomalus's killer toxins damage the $\beta$-glucan scaffold in the cell walls of sensitive yeast cells and thereby induce cell death by osmotic lysis (Muccilli et al., 2013). Thus far, the mode of action of the killer toxins Kwkt and PMKT, which are active against B. bruxellensis, have not yet been unravelled. It is not yet clear whether all the toxins that recognise $\beta-1,6$-glucan as receptor display glucanase activity specifically targeting the cell wall glucan of sensitive cells, or whether they are cell wall glucanases that incidentally display killer activity. The following paragraph will discuss this issue.

\section{Do exoglucanases possess killer activity?}

The yeast cell wall of Saccharomyces cerevisiae is composed of 50\% $\beta$-D-1,3-glucan, which contains ca. 5\% $\beta-1,6$ linked branches; $15 \% \quad \beta$-D-1,6-glucan containing ca. $14 \% \beta-1,3$ linked branches; and mannoproteins and chitin (0.6 to 9\%) (Kollár et al., 1995; Santos et al., 2000). In recent literature (İzgü \& Altinbay, 2004; İzgü et al., 2006; Comitini et al., 2009; Muccilli et al., 2013), growing evidence suggests that the killer activity of some killer toxins occurs through glucanase activity. Fungal $\beta-1,3$-glucanases play a role in metabolic and morphogenetic events in the fungal cell, including cell wall extension, hyphal branching, sporulation, budding, autolysis during development and differentiation, and in the mobilisation of $\beta$-glucans in response to conditions of carbon and energy source exhaustion (Peng et al., 2009).

Exo-glucanase activity has been detected in killer toxinproducing yeast species of $W$. anomalus, P. membranifaciens, W. saturnus, $P$. anomala strain $\mathrm{K}$ and Candida oleophila (Jijakli \& Lepoivre, 1998; Masih \& Paul, 2002; Bar-Shimon et al., 2004; İzgü \& Altinbay, 2004; İzgü et al., 2006; Friel et al., 2007; Wang et al., 2007; Xu et al., 2011; Guo et al., 2012). Three killer strains of $W$. anomalus (BCU24, BS91 and BCA15) exhibited killer activity against a $S$. cerevisiae wild type strain, while mutants deficient in $\beta-1,6$-glucan were resistant to the toxins of the strains. The exoglucanase (WaExg1) proteins of the $W$. anomalus killer strains, BCU24 and BS91, display identical amino acid sequences to each other and exhibit $99 \%$ similarity to the $\beta$-glucanase of $P$. anomala strain $\mathrm{K}$, while the amino acid sequence of



HMK: Inhibition of $\beta$-glucan synthesis

FIGURE 1

A schematic representation of the mode of action of the killer toxins of Kluyveromyces lactis, Pichia kluyveri, Pichia membranifaciens (PMKT2), Tetrapisispora phaffii (Kpkt) and Williopsis mrakii (HMK), as described by Middelbeek et al. (1980); Yamamoto et al. (1986); Magliani et al. (1997); Comitini et al. (2009) and Santos et al. (2013). (․ㅣ: Killer toxin. 
the strain BCA15 perfectly matches the $\beta$-glucanase of $P$. anomala strain K. Furthermore, the $W a E X G 2$ sequences of the killer strains are identical to those from $P$. anomala strain $\mathrm{K}$ (Muccilli et al., 2013). The authors concluded that killer activity is probably due to $\beta-1,6$ and/or $\beta-1,3$-glucanase activity.

$P$. anomala strain $\mathrm{K}$ is an efficient and reliable antagonist of $B$. cinerea and Penicillium expansum in apples. The disruption of $P$. anomala's exo-glucanase genes $P a E X G 1$ and $P a E X G 2$ resulted in reduced efficiency $-8 \%$ from $71 \%$ in the biocontrol of B. cinerea in apples (Friel et al., 2007). Growth of $B$. cinerea in the presence of $P$. membranifaciens resulted in extensive damage to the fungal cell wall, with complete rupture and fragmentation of the hyphal filaments of $B$. cinerea. $P$. membranifaciens showed increased production of both endo- and exo- $\beta$-1,3-glucanase in the presence of cell wall preparations of $B$. cinerea (Masih \& Paul, 2002). In addition, in another study, higher exo- $\beta-1,3-$ glucanase activity was observed in culture media with cell wall preparations of $B$. cinerea as carbon source (Jijakli \& Lepoivre, 1998) compared to when glucose was the carbon source.

A similar stimulatory effect was observed with $C$. oleophila: the production of exo- $\beta$-1,3-glucanase was induced in the presence of Penicillium digitatum. Biocontrol in fruit using both wild type $(C$. oleophila) and exo- $\beta$-1,3-glucanase over-expressing transformants showed no difference in inhibition, as they both showed similar inhibitory effects (Bar-Shimon et al., 2004). N-terminal sequencing of the killer toxin of $P$. anomala NCYC 432 yielded a short sequence with $100 \%$ identity to the mature exo- $\beta$-1,3-glucanase of $P$. anomala strain K (İzgü et al., 2006) that is linked to the killer effect of this strain. Similarly, internal amino acid sequencing of the K5-type killer protein of $P$. anomala NCYC 434 yielded $100 \%$ identity with the exo- $\beta$-1,3-glucanase of $P$. anomala strain K (İzgü \& Altinbay, 2004). All these studies clearly indicate that exo-glucanases may display some form of killer activity against other yeast species or filamentous fungi. Recently, the killer toxin Kpkt has been shown to be coded by the gene $\mathrm{Tp} B G L 2$, of which the $T$. phaffii strain without this gene lost both $\beta$-glucanase and killer activity (Oro et al., 2013).

Currently, killer toxins are defined as secreted proteins that exhibit antimicrobial activity towards susceptible yeasts of the same species or related species. Thus, this definition of killer toxins is based mainly on antimicrobial activity. However, it does not exclude killer toxins that may display other primary functions such as enzymatic activity. As such, the definition of killer toxins should not be focused on antimicrobial activity only. It should rather encompass other characteristics of the secreted protein(s), such as exoglucanase activity. This would therefore increase the scope of exploitation of these secreted proteins to agents that can aid in the clarification, filtration and ageing of young wines, in addition to inhibiting spoilage microorganisms.

\section{SUMMARY AND FUTURE PROSPECTS}

For centuries, metabolites and by-products of microbial growth have been used for human benefit, and this still holds true in the $21^{\text {st }}$ century. In wine, microbial contamination is a major concern despite the widespread use of commercial preservatives such as $\mathrm{SO}_{2}$. Therefore, new preservation products or methods to prevent or control microbial contamination are actively sought. Ideally, such products or methods should not have application limitations (e.g. cause allergic reactions in consumers, alter the quality of the product) and the method(s) should be applied at minimal cost. The use of physical techniques and chemical preservatives to combat spoilage microorganisms has proven to have limited efficiency and application. This is attributed to the fact that physical techniques have been found to be detrimental to the sensorial properties of wine, and chemical preservatives inhibit or control the proliferation of contaminating microorganisms efficiently when applied in high concentrations.

The use of killer toxins has been explored under experimental conditions, and the findings from such endeavours have revealed that they can be applied as alternatives in controlling microbial spoilage. In particular, the killer toxins of non-Saccharomyces yeasts, which have a broader spectrum of activity, could be exploited to control spoilage yeasts. Killer toxins from the yeasts $K$. wickerhamii, $P$. anomala and $P$. membranifaciens have indeed been shown to have potential in controlling $B$. bruxellensis. However, they have not been as well characterised as those of $S$. cerevisiae and further investigations are needed to clarify their genetic origin and mode of action. Preliminary reports have shown that these are diverse and poorly understood as yet.

The binding receptors of some of the non-Saccharomyces killer toxins provide strong evidence in support of the hypothesis that these killer toxins are glucanases or display glucanase activity. Nevertheless, the following questions remain unanswered: are the killer toxins inherent glucanases that happen to possess antimicrobial activity towards other yeasts, and can these killer toxins be used as biopreservatives in wine and in the food and beverage industry? Although evidence exists of their biopreservative potential, these killer toxins have only been used for research purposes and will have to be approved by the OIV and/or the national regulations of exporting countries before they could be used for commercial purposes.

\section{LITERATURE CITED}

Arriagada-Carrazana, J.P., Saez-Navarrete, C. \& Brodeu, E., 2005. Membrane filtration effects on aromatic and phenolic quality of Cabernet Sauvignon wines. J. Food Eng. 68, 363-368.

Barata, A., Caldeira, J., Botelheiro, R., Pagliara, D., Malfeito-Ferreira, M. \& Loureiro, V., 2008. Survival patterns of Dekkera bruxellensis in wines and inhibitory effect of sulphur dioxide. Int. J. Food Microbiol. 121, 201-207.

Barata, A., Nobre, A., Correia, P., Malfeito-Ferreira, M. \& Loureiro, V., 2006. Growth and 4-ethylphenol production by the yeast Pichia guilliermondii in grape juices. Am. J. Enol. Vitic. 57, 133-138.

Bar-Shimon, M., Yehuda, H., Cohen, L., Weiss, B., Kobeshnikov, A., Daus, A., Goldway, M., Wisniewski, M. \& Droby, S., 2004. Characterization of extracellular lytic enzymes produced by the yeast biocontrol agent Candida oleophila. Curr. Genet. 45, 140-148.

Benito, S., Palomero, F., Calderón, F. \& Súarez-Lepe, J.A., 2009. Factors affecting the hydroxycinnamate decarboxylase/vinylphenol reductase activity of Dekkera/Brettanomyces: Application for Dekkera/Brettanomyces control in red wine making. J. Food Sci. 74, 1-22. 
Bussey, H., 1972. Effects of yeast killer factors on sensitive cells. Nature New Biol. 235, 73-75.

Bussey, H. \& Skipper, N., 1975. Membrane-mediated killing of Saccharomyces cerevisiae by glycoproteins from Torulopsis glabrata. J. Bacteriol. 124, 476-483.

Cailliez, J.C., Séguy, N., Aliouat, E.M., Polonelli, L., Camus, D. \& DeiCas, E., 1994. The yeast killer phenomenon: A hypothetical way to control Pneumocystis carinii pneumonia. Med. Hypotheses 43, 167-171.

Chatonnet, P., Dubourdieu, D. \& Boidron, J.N., 1995. The influence of Brettanomyces/Dekkera sp. yeasts and lactic acid bacteria on the ethyphenol content of red wines. Am. J. Enol. Viticult. 46, 463-468.

Chatonnet, P., Dubourdieu, D., Boidron, J.N. \& Pons, M., 1992. The origin of ethylphenols in wines. J. Sci. Food Agric. 60, 165-178.

Ciani, M. \& Comitini, F., 2011. Non-Saccharomyces wine yeasts have a promising role in biotechnological approaches to winemaking. Ann. Microbiol. 61, 25-32.

Ciani, M. \& Fatichenti, F., 2001. Killer toxin of Kluyveromyces phaffii DBVPG 6076 as a biopreservative agent to control apiculate wine yeasts. Appl. Environ. Microbiol. 67, 3058-3063.

Ciani, M., Maccarelli, F. \& Fatichenti, F., 2003. Growth and fermentation behaviour of Brettanomyces/Dekkera yeasts under different conditions of aerobiosis. World J. Microbiol. Biotechnol. 19, 419-422.

Cleveland, J., Montville, T.J., Nes, J.F. \& Chikindas, M.L., 2001. Bacteriocins: Safe, natural antimicrobials for food preservation. Int. J. Food Microbiol. 71, 1-20.

Comitini, F. \& Ciani, M., 2010. The zymocidial activity of Tetrapisispora phaffii in the control of Hanseniaspora uvarum during the early stages of winemaking. Lett. Appl. Microbiol. 50, 50-56.

Comitini, F. \& Ciani, M., 2011. Kluyveromyces wickerhamii killer toxin: Purification and activity towards Brettanomyces/Dekkera yeasts in grape must. FEMS Microbiol. Lett. 316, 77-82.

Comitini, F., De Ingeniis, J., Pepe, L., Mannazzu, I. \& Ciani, M., 2004b. Pichia anomala and Kluyveromyces wickerhamii killer toxins as new tools against Dekkera/Brettanomyces spoilage yeasts. FEMS Microbiol. Lett. $238,235-240$.

Comitini, F., Di Pietro, N., Zacchi, L., Mannazzu, I. \& Ciani, M., 2004a. Kluyveromyces phaffi killer toxin active against wine spoilage yeasts: Purification and characterization. Microbiol. 150, 2535-2541.

Comitini, F., Mannazzu, I. \& Ciani, M., 2009. Tetrapisispora phaffii killer toxin is a highly specific $\beta$-glucanase that disrupts the integrity of the yeast cell wall. Microb. Cell Fact. 27, 8-55.

Costa, A., Barata, A., Malfeito-Ferreira, M. \& Loureiro, V., 2008. Evaluation of the inihibitory effect of dimethyl dicarbonate (DMDC) against wine microorganisms. Food Microbiol. 25, 422-427.

Couto, J.A., Neves, F., Campos, F. \& Hogg, T., 2005. Thermal inactivation of the wine spoilage yeasts Dekkera/Brettanomyces. Int. J. Food Microbiol. 104, 337-344.

Curtin, C.D., Borneman, A.R., Chambers P.J. \& Pretorius, I.S., 2012a. Denovo assembly and analysis of the heterozygous triploid genome of the wine spoilage yeast Dekkera bruxellensis AWRI1499. PLoS ONE 7(3): e33840.

Curtin, C., Kennedy, E. \& Henschke, P.A., 2012b. Genotype-dependent sulphite tolerance of Australian Dekkera (Brettanomyces) bruxellensis wine isolates. Lett. Appl. Microbiol. 55, 56-61.

Dai, Y., Normand, M.D., Weiss, J. \& Peleg, M., 2010. Modelling the efficacy of triplet antimicrobial combinations: yeast suppression by lauric arginate, cinnamic acid and sodium benzoate or potassium sorbate as a case study. J. Food Prot. 73, 515-523.
De Ingeniis, J., Raffaelli, N., Ciani, M. \& Mannazzu, I., 2009. Pichia anomala DBVPG 3003 secretes a ubiquitin-like protein that has antimicrobial activity. Appl. Environ. Microbiol. 75, 1129-1134.

Delfini, C., Gaia, P., Schellino, R., Pagliara, A. \& Ambrò, A., 2002. Fermentability of grape must after inhibition with dimethyl dicarbonate (DMDC). J. Agric. Food Chem. 50, 5605-5611.

Dias, L., Dias, S., Sancho, T., Stender, H., Querol, A., Malfeito-Ferreira, M. \& Loureiro, V., 2003b. Identification of yeasts isolated from wine-related environments and capable of producing 4-ethylphenol. Food Microbiol. 20, 567-574.

Dias, L., Pereira-da-Silva, S., Tavares, M., Malfeito-Ferreira, M. \& Loureiro, V., 2003a. Factors affecting the production of 4-ethylphenol by the yeast Dekkera bruxellensis in enological conditions. Food Microbiol. $20,377-384$.

Du Toit, M. \& Pretorius, I.S., 2000. Microbial spoilage and preservation of wine: Using weapons from nature's own arsenal - A review. S. Afr. J. Enol. Vitic. 21, 74-96

Enrique, M., Ibáñez, A., Marcos, J.F., Yuste, M., Martínez, M., Vallés, S. \& Manzanares, P., 2010. $\beta$-Glucanases as a tool for the control of wine spoilage yeasts. Food Microbiol. Safety 75, M41-M45.

Fredericks, I N., Du Toit, M. \& Krügel, M., 2011. Efficacy of ultraviolet radiation as an alternative technology to inactivate microorganisms in grape juices and wines. Food Microbiol. 28, 510-517.

Freedman, B.J., 1977. Asthma induced by sulphur dioxide, benzoate and tartrazine contained in orange drinks. Clin. Exp. Allergy 7, 407-415.

Friel, D., Pessoa, N.M.G., Vandenbol, M. \& Jijakli, M.H., 2007. Separate and combined disruptions of two exo- $\beta-1,3$-glucanase genes decrease the efficiency of Pichia anomala (strain K) biocontrol against Botrytis cinerea on apple. Mol. Plant Microbe Interact. 20,371-379.

Fugelsang, K.C. \& Edwards, C.G., 2007. Microbial ecology during vinification. In: Fuselsang, K.C. \& Edwards, C.G. (eds). Wine microbiology: Practical applications and procedures, Springer Science + Business Media, LLC, New York. pp. $82-101$.

Godoy, L., Garrido, D., Martínez, C., Saavedra, J., Combina, M. \& Ganga M., 2009. Study of the coumarate decarboxylase and vinylphenol reductase activities of Dekkera bruxellensis (anamorph Brettanomyces bruxellensis) isolates. Lett. Appl. Microbiol. 48: 452-457.

Godoy, L., Martinez, C., Carrasco N. \& Ganga M., 2008. Purification and characterization of a p-coumarate decarboxylase and a vinylphenol reductase from Brettanomyces bruxellensis. Int. J. Food Microbiol. 127, 6-11.

Gómez-Rivas, L., Escudero-Abarca, B.I., Aguilar-Uscanga, M.G., HaywardJones, P.M., Mendoza, P. \& Ramírez, M., 2004. Selective antimicrobial action of chitosan against spoilage yeasts in mixed culture fermentations. J. Ind. Microbiol. Biotechnol. 31, 16-22.

Goretti, M., Turchetti, B., Buratta, M., Branda, E., Corazzi, L., VaughanMartini, A. \& Buzzini, P., 2009. In vitro antimycotic activity of a Williopsis saturnus killer protein against food spoilage yeasts. Int. J. Food Microbiol. $131,178-182$.

Granato, T.M., Romano, D., Vigentini, I., Foschino, R.C. Monti, D., Mamone, G., Ferranti, P., Nitride, C., Iametti, S., Bonomi, F. \& Molinari, F., 2014. New insights on the features of the vinyl phenol reductase from the wine-spoilage yeast Dekkera/Brettanomyces bruxellensis. Ann. Microbiol. DOI:10.1007/s13213-014-0864-5

Guillen, A.C., Kenchinski, C.P. \& Manfroi, V., 2010. The use of ozone in a CIP system in the win industry. Ozone: Sci. Eng. 32, 355-360.

Guo, F.-J., Ma, Y., Xu, H.-M., Wang, X.-H. \& Chi, Z.-M., 2012. A novel killer toxin produced by the marine-derived yeast Wickerhamomyces anomalus YF07b. Antonie van Leewenhoek 103, 737-746. 
Gutiérrez, A.R., Epifanio, S., Garijo, P., López, R. \& Santamaría, P., 2001. Killer yeasts: Incidence in the ecology of spontaneous fermentation. Am. J. Enol. Vitic. 52, 352-356.

Guzzon, R., Nardin, T., Micheletti, O., Nicolini, G. \& Larcher, R., 2013. Antimicrobial activity of ozone. Effectiveness against the main wine spoilage microorganisms and evaluation of impact on simple phenols in wine. Aust. J. Grape Wine Res. 19, 180-188.

Harris, V., Ford, C.M. Jiranek, V. and Grbin, P.R., 2009. Survey of enzyme activity responsible for phenolic off-flavour production by Dekkera and Brettanomyces yeast. Appl. Microbiol. Biotechnol. 81, 1117-1127.

İzgü, F. \& Altinbay, D., 2004. Isolation and characterization of the K5-type yeast killer protein and its homology with an exo- $\beta-1,3$-glucanase. Biosci. Biotechnol. Biochem. 68, 685-693.

İzgü, F., Altinbay, D. \& Acun, T., 2006. Killer toxin of Pichia anomala NYCY432; purification, characterization and its exo-B-1,3-glucanase activity. Enzyme Microb. Technol. 39, 669-676.

Jijakli, M.H. \& Lepoivre, P., 1998. Characterization of an exo- $\beta-1,3-$ glucanase produced by Pichia anomala strain K, antagonist of Botrytis cinerea on apples. Phytopathology 88, 335-343.

Kheir, J., Salameh, D., Strehaiana, P., Brandam, C. \& Lteif, R., 2013. Impact of volatile phenols and their precursors on wine quality and control measures of Brettanomyces/Dekkera yeasts. Eur. Food Res. Technol. 237, 655-671.

Kollár, R., Petráková, E., Ashwell, G., Robbins, P.W. \& Cabib, E., 1995. Architecture of the yeast cell wall - the linkage between chitin and $\beta(1-3)$ glucan. J. Biol. Chem. 270, 1170-1178.

Liu, G-L., Chi, Z., Wang, C-Y., Zhi-Peng, W., Li, Y. \& Zhen-Ming, C., 2013. Yeast killer toxins, molecular mechanisms of their action and their application. Crit. Rev. Biotechnol. DOI:10.3109/07388551.2013.833582

Liu, S.-Q. \& Tsao, M., 2009. Inhibition of spoilage yeasts in cheese by killer yeast Williopsis saturnus var. saturnus. Int. J. Food Microbiol. 131, 280 282.

Loureiro, V. \& Malfeito-Ferreira, M., 2003. Spoilage yeasts in the wine industry. Int. J. Food Microbiol. 86, 23-50.

Loureiro, V. \& Malfeito-Ferreira, M., 2006. Food spoilage microorganisms. Boca Raton: Woodhead Publishing.

Lowes, K.F., Shearman, C.A., Payne, J., MacKenzie, D., Archer, D.B., Merry, R.J. \& Gasson, M.J., 2000. Prevention of yeast spoilage in feed and food by the yeast mycocin HMK. Appl. Environ. Microbiol. 66, 1066-1076.

Lustrato, G., Alfano, G., Belli, C., Grazia, L., Lorizzo, M. \& Ranalli, G., 2006. Scaling-up in industrial winemaking using low electric current as an alternative to sulfur dioxide addition. J. Appl. Microbiol. 101, 682-690.

Lustrato, G., Vigentini, I., De Leonardis, A., Alfano, G., Tirelli, A., Foschino, R. \& Ranalli, G., 2010. Inactivation of wine spoilage yeasts Dekkera bruxellensis using low electric current treatment (LEC). J. Appl. Microbiol. 190, 594-604.

Magliani, W., Conti, S., Gerloni, M., Bertolotti, D. \& Polonelli, L., 1997. Yeast killer systems. Clin. Microbiol. Rev. 10, 369-400.

Mannazzu, I., Clementi, F. \& Ciani, M., 2002. Strategies and criteria for the isolation and selection of autochthonous starters. In: Ciani, M. (ed). Biodiversity and biotechnology of wine yeasts. Research Signpost, Trivandrum, India. pp. $19-33$.

Manzanares, P., Vallés, S. \& Viana, F., 2011. Non-Saccharomyces yeasts in the wine making process. In: Santiago, C.A.V., Munoz, R. \& Garcia R.G. (eds). Molecular wine microbiology. Academic Press, Academic Press, Valencia, Spain, pp. 85-110.
Marsellés-Fontanet, À.R., Puig, A., Olmos, P., Mínguez-Sanz, S. \& MartínBelloso, O., 2009. Optimising the inactivation of grape juice spoilage organisms by pulse electric fields. Int. J. Food Microbiol. 130, 159-165.

Masih, E.I. \& Paul, B., 2002. Secretion of $\beta$-1,3-glucanases by the yeast Pichia membranifaciens and its possible role in the biocontrol of Botrytis cinerea causing grey mold disease of the grapevine. Curr. Microbiol. 44, 391-395.

Middelbeek, E.J., Stumm, C. \& Vogels, G.D., 1980. Effects of Pichia kluyveri killer toxin on sensitive cells. Antonie van Leeuwenhoek 46, 205 220 .

Millet, V. \& Lonvaud-Funel, A., 2000. The viable but non-culturable state of wine microorganisms during storage. Lett. Appl. Microbiol. 30, 136-141.

Monagas, M., Gómez-Cordovés, C. \& Bartolomé, B., 2006. Evolution of the phenolic content of red wines from Vitis vinifera L. during ageing in bottle. Food Chem. 95, 405-412

Moreno, N.J. \& Azpilicueta, C.A., 2006. The development of esters in filtered and unfiltered wines that have been aged in oak barrels. Int. J. Food Sci. Technol. 41, 155-161.

Muccilli, S., Wemhoff, S., Restuccia, C. \& Meinhardt, F., 2013. Exoglucanase-encoding genes from three Wickerhamomyces anomalus killer strains isolated from olive brine. Yeast 30, 33-43.

Novotná, D., Flegelová, H. \& Janderová, B., 2004. Different action of killer toxins $\mathrm{K} 1$ and $\mathrm{K} 2$ on the plasma membrane and the cell wall of Saccharomyces cerevisiae. FEMS Yeast Res. 4, 803-813.

Oelofse, A., 2008. Investigating the role of Brettanomyces and Dekkera during winemaking. Thesis, Stellenbosch University, Private Bag X1, 7602 Matieland (Stellenbosch), South Africa.

Oelofse, A., Pretorius, I.S. \& Du Toit, M., 2008. Significance of Brettanomyces and Dekkera during winemaking: A synoptic review. S. Afr. J. Enol. Vitic. 29, 128-144.

OIV, 2001. Wine microbiological stabilization by the addition of dimethyldicarbonate.

Oro, L., Zara, S., Fancellu, F., Mannazzu, I., Budroni, M., Ciani, M. \& Comitini, F., 2013. TpBGL2 codes for a Tetrapisispora phaffii killer toxin active against wine spoilage yeasts. FEMS Yeast Res. doi:10.1111/15671364.12126

Oro, L., Ciani, M. \& Comitini, F., 2014. Antimicrobial activity of Metschnikowia pulcherrima on wine yeasts. J. Appl. Microbiol. 116, 12091217 .

Palpacelli, V., Ciani, M. \& Rosini, G., 1991. Activity of different 'killer' yeasts on strains of yeast species undesirable in the food industry. FEMS Microbiol. Lett. 84, 75-78.

Peng, Y., Chi, Z.-M., Wang, X.-H. \& Li, J., 2009. Purification and molecular characterization of exo- $\beta$-1,3-glucanases from the marine yeast Williopsis saturnus WC91-2. Appl. Microbiol. Biotechnol. 85, 85-94.

Peri, C., Riva, M. \& Decio, P., 1988. Crossflow membrane filtration of wines: Comparison of performance of ultrafiltration, microfiltration, and intermediate cut-off membranes. Am. J. Enol. Vitic. 39, 162-168.

Philliskirk, G. \& Young, T.W., 1975. The occurrence of killer character in yeasts of various genera. Antonie van Leewenhoek 41, 147-151.

Piškur, J., Ling, Z., Marcet-Houben, M., Ishchuk, O.P., Aerts, A., LaButti, K., Copeland, A., Lindquist, E., Barry, K., Compagno, C., Bisson, L., Grigoriev, I. V., Gabaldón, T. \& Phister, T., 2012. The genome of wine yeast Dekkera bruxellensis provides a tool to explore its food-related properties. Int. J. Food Microbiol. 157, 202-209. 
Puértolas, E., López, N., Condón, S., Raso, J. \& Álvarez, I., 2009. Pulsed electric fields inactivation of wine spoilage yeast and bacteria. Int. J. Food Microbiol. 130, 49-55.

Renouf, V., Strehaiano, P. \& Lonvaud-Funel, A., 2008. Effectiveness of dimethyldicarbonate to prevent Brettanomyces bruxellensis growth in wine. Food Cont. 19, 208-216.

Rodríguez-Cousin, N., Maqueda, M., Ambrona, J., Zamora, E., Esteban, R. \& Ramírez, M., 2011. A new wine Saccharomyces cerevisiae killer toxin (Klus), encoded by a double-stranded RNA virus, with broad antifungal activity is evolutionarily related to a chromosomal host gene. Appl. Environ. Microbiol. 77, 1822-1832.

Romano, A., Perello, M.C., De Revel, G. \& Lonvaud-Funel, A., 2008 Growth and volatile compound production by Brettanomyces/Dekkera bruxellensis in red wine. J. Appl. Microbiol. 104, 1577-1585.

Santos, A. \& Marquina, D., 2004. Killer toxin of Pichia membranifaciens and its possible use as a biocontrol agent against grey mould disease of grapevine. Microbiology 150, 2527-2534.

Santos, A., Alonso, A., Belda, I. \& Marquina, D., 2013. Cell cycle arrest and apoptosis, two alternative mechanisms for PMKT2 killer activity. Fungal Genet. Biol. 50, 44-54.

Santos, A., Marquina, D., Barroso, J. \& Peinado, J.M., 2002. (1-6)- $\beta$-Dglucan as the cell wall binding site for Debaryomyces hansenii killer toxin. Lett. Appl. Microbiol. 34, 95-99.

Santos, A., Marquina, D., Leal, J.A. \& Peinado, J.M., 2000. (1-6)- $\beta$-Dglucan as cell wall receptor for Pichia membranificiens killer toxin. Appl. Environ. Microbiol. 66, 1809-1813.

Santos, A., Mauro, M.S., Bravo, E. \& Marquina, D., 2009. PMKT2, a new killer toxin from Pichia membranifaciens, and its promising biotechnological properties for control of the spoilage yeast Brettanomyces bruxellensis. Microbiology 155, 624-634

Santos, A., Navascués, E., Bravo, E. \& Marquina, D., 2011. Ustilago maydis killer toxin as a new tool for the biocontrol of the wine spoilage yeast Brettanomyces bruxellensis. Int. J. Food Microbiol. 145, 147-154.

Schmid, F., Grbin, P., Yap, A. \& Jiranek, V., 2011. Relative efficacy of high-pressure hot water and high-power ultrasonics for wine oak barrel sanitization. Am. J. Enol. Vitic. 62, 519-526.

Schmitt, M.J. \& Breinig, F., 2002. The viral killer system in yeast: From molecular biology to application. FEMS Microbiol. Rev. 26, 257-276.

Schmitt, M.J. \& Breinig, F., 2006. Yeast viral killer toxins: Lethality and self-protection. Nature Rev. Microbiol. 4, 212-221.

Schmitt, M.J. \& Neuhausen, F., 1994. Killer toxin-secreting doublestranded RNA mycoviruses in the yeasts Hanseniaspora uvarum and Zygosaccharomyces bailii. J. Virol. 68, 1765-1772.

Selvakumar, D., Miyamoto, M., Furuichi, Y. \& Komiyama, T., 2006. Inhibition of fungal b-1,3-glucan synthase and cell growth by HM-1 killer toxin single-chain anti-idiotypic antibodies. Antimicrob. Agents Chemother. 50, 3090-3097.

Skipper, N. \& Bussey, H., 1977. Mode of action of yeast toxins: Energy requirement for Saccharomyces cerevisiae killer toxin. J. Bacteriol. 129, 668-677.
Steinlauf, R., Peery, T., Koltin, Y. \& Bruenn, J., 1988. The Ustilago maydis virus-encoded toxin - effect of KP6 on sensitive cells and spheroplasts. Exp. Mycol. 12, 264-274.

Suárez, R., Suárez-Lepe, J.A., Morata, A. \& Calderón, F., 2007. The production of ethylphenols in wine by yeasts of the genera Brettanomyces and Dekkera: A review. Food Chem. 102, 10-21.

Tredoux, H.G., Tracey, R.P. \& Tromp, A., 1986. Killer factor in wine yeasts and its effect on fermentation. S. Afr. J. Enol. Vitic. 7, 105-112.

Tchobanov, I., Gal, L., Guilloux-Benatier, M., Remize, F., Nardi, T., Guzzo, J., Serpaggi, V. \& Alexandre, H., 2008. Partial vinylphenol reductase purification and characterization from Brettanomyces bruxellensis. FEMS Microbiol. Lett. 284, 213-217.

Umiker, N.L., Descenzo, R.A., Lee, J. \& Edwards, C.G., 2013. Removal of Brettanomyces bruxellensis from red wine using membrane filtration. J. Food Proc. Pres. 37, 799-805.

Van Esch, F., 1992. Yeast in soft drinks and concentrated fruit juices. Brygmesteren 4, 9-20.

Van Vuuren, H.J.J. \& Jacobs, C.J., 1992. Killer yeasts in the wine industry: A review. Am. J. Enol. Viticult. 43, 119-128.

Walker, G.M., McLeod, A.H. \& Hodgson, V.J., 1995. Interactions between killer yeasts and pathogenic fungi. FEMS Microbiol. Lett. 127, 213-222.

Wang, X., Chi, Z., Yue, L. \& Li, J., 2007. Purification and characterization of killer toxin from a marine yeast Pichia anomala YF707b against the pathogenic yeast in crab. Curr. Microbiol. 55, 396-401.

Wedral, D., Shewfelt, R. \& Frank, J., 2010. The challenge of Brettanomyces in wine. LTW - Food Sci. Technol. 43, 1474-1479.

Wickner, R.B., 1979. The killer double-stranded RNA plasmids of yeast. Plasmid 2, 303-322.

Wilson, C. \& Whittaker, P. A., 1989. Factors affecting activity and stability of the Kluyveromyces lactis killer toxin. Appl. Environ. Microbiol. 55, 695699

Woods, D.R. \& Bevan, E.A., 1968. Studies on the nature of the killer factor produced by Saccharomyces cerevisiae. J. Gen. Microbiol. 51, 115-126.

Xu, J.-L., Zhang, X., Sun, H.-Y. \& Chi, Z.-M., 2011. Disruption of the gene encoding $\beta$-1,3-glucanase in marine-derived Williopsis saturnus WC91-2 enhances its killer toxin activity. Marine Biotechnol. 14, 261-269.

Yamamoto, T., Hiratani, T., Hirata, H., Imai, M. \& Yamaguchi, H., 1986. Killer toxin from Hansenula mrakii selectively inhibits cell wall synthesis in a sensitive yeast. FEBS Lett. 197, 50-54

Yap, A., Schmid, F., Jiranek, V., Grbin, P. \& Bates, D., 2008. Inactivation of Brettanomyces/ Dekkera in wine barrels by high power ultrasound. Wine Ind. J. 23, 32-40.

Yap, N. A., de Barros Lopes, M., Langridge, P. \& Henschke, P. A., 2000. The incidence of killer activity on non-Saccharomyces yeasts towards indigenous yeast species of grape must: potential application in wine fermentation. J. Appl. Microbiol. 89, 381-389.

Young, T.W. \& Yagiu, M., 1978. A comparison of the killer character in different yeasts and its classification. Antonie van Leeuwenhoek 44, 59-77.

Zuehlke, J.M., Petrova, B. \& Edwards, C.G., 2013. Advances in the contro of wine spoilage by Zygosaccharomyces and Dekkera/Brettanomyces. Ann. Rev. Food Sci. Technol. 4, 57-78. 